Co-migration of phytate with cereal beta-glucan and its role in starch hydrolysis in-vitro

\title{
Wang, Yu-Jie
}

2020-05

Wang , Y-J , Yang , L \& Sontag-Strohm , T 2020 , ' Co-migration of phytate with cereal beta-glucan and its role in starch hydrolysis in-vitro ', Journal of Cereal Science , vol. 93 , 102933 . https://doi.org/10.1016/j.jcs.2020.102933

http://hdl.handle.net/10138/326597

https://doi.org/10.1016/j.jcs.2020.102933

cc_by_nc_nd

acceptedVersion

Downloaded from Helda, University of Helsinki institutional repository.

This is an electronic reprint of the original article.

This reprint may differ from the original in pagination and typographic detail.

Please cite the original version. 
Manuscript Details

Manuscript number YJCRS 2019 716 R2

Title: Co-migration of phytate with cereal $\beta$-glucan and its role in starch hydrolysis invitro

Article type Research Paper

Keywords Cereal $\beta$-glucan; phytic acid; ethanol precipitation; starch hydrolysis.

Taxonomy Cereal Grain Enzymes, Cereal Grain Carbohydrates, Cereal Grain Dietry Fibre

Corresponding Author Yu-Jie Wang

Corresponding Author's

Institution

Nestlé Research Center

Order of Authors Yu-Jie Wang, Lingxi Yang, Tuula Sontag-Strohm 
3 Yu-Jie Wang *, Lingxi Yang ${ }^{1}$, Tuula Sontag-Strohm²

4 Department of Food and Nutrition, Division of Food Technology, University of Helsinki, Agnes $5 \quad$ Sjöbergin katu 2, P.O. Box 66, FIN-00014 Helsinki, Finland

6 12Email address: lucyyoung24@hotmail.com; tuula.sontag-strohm@helsinki.fi

7 *corresponding author: Tel.: +41 76683 0924; E-mail address: wangyujie.nfu@gmail.com 8 


\section{Highlights}

- Intrinsic phytic acid in $\beta$-glucan sample reduced starch hydrolysis in vitro.

- Viscosity of $\beta$-glucan also contributed to the reduction of starch hydrolysis.

- Phytic acid co-precipitated with $\beta$-glucan when using ethanol in isolation.

- Phytic acid did not co-precipitate with $\beta$-glucan when using $20 \%\left(\mathrm{NH}_{4}\right)_{2} \mathrm{SO}_{4}$. 


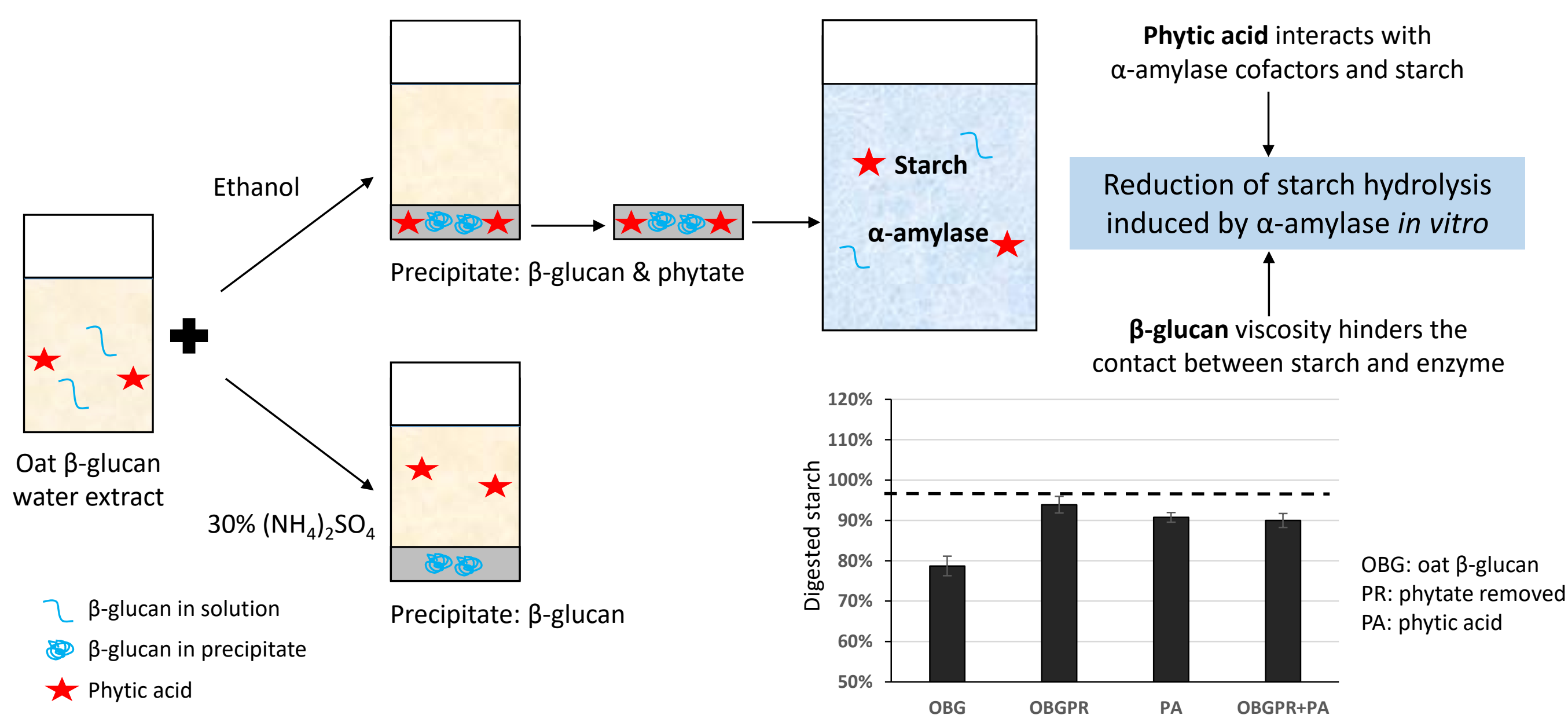

Co-migration of phytate with $\beta$-glucan during extraction (precipitation) \& Contribution of phytate to reduction of starch hydrolysis in vitro 
3 Yu-Jie Wang *, Lingxi Yang ${ }^{1}$, Tuula Sontag-Strohm²

4 Department of Food and Nutrition, Division of Food Technology, University of Helsinki, Agnes $5 \quad$ Sjöbergin katu 2, P.O. Box 66, FIN-00014 Helsinki, Finland

6 12Email address: lucyyoung24@hotmail.com; tuula.sontag-strohm@helsinki.fi

7 *corresponding author: Tel.: +41 76683 0924; E-mail address: wangyujie.nfu@gmail.com 8 
This study investigated the mechanisms of the co-migration of phytic acid during $\beta$-glucan isolation and its contribution to the retardation of starch hydrolysis in vitro. During the isolation, phytic acid precipitated together with $\beta$-glucan when ethanol was added as the precipitation solvent. The precipitation of phytic acid was reduced by lowering the $\mathrm{pH}$ or the ethanol concentration. When $20 \%$ $\left(\mathrm{NH}_{4}\right)_{2} \mathrm{SO}_{4}$ was used as the precipitation solvent, only minor phytic acid was found in isolated $\beta$ glucan, because phytic acid did not precipitate by this solvent. In the in vitro starch hydrolysis test, the isolated oat $\beta$-glucan (OBG) containing 3.9\% co-migrated phytic acid showed better retardation effect than OBG containing $0.6 \%$ phytic aicd. Therefore, we concluded that the co-migration of phytic acid was dependent on the chosen isolation procedure and conditions, and both intrinsic phytic acid and viscosity contributed to the retardation of starch hydrolysis.

\section{Keywords}

24 Cereal $\beta$-glucan, phytic acid, phytate, ethanol precipitation, starch hydrolysis 


\section{Introduction}

Cereal $\beta$-( $(1 \rightarrow 3),(1 \rightarrow 4)$-D-glucan is a water soluble polysaccharide that has been shown to reduce starch digestion and post-prandial glucose and insulin responses (Kim et al., 2013; Makelainen et al., 2007; Regand et al., 2011). This effect was suggested to be attributed to the ability of $\beta$-glucan to form viscous solution at low concentrations. In the digestive tract, the viscous solution of $\beta$-glucan acts as a barrier, reducing absorption and diffusion of the nutrients such as glucose, lipid and bile acid directly or via limiting the contact between the digestive enzymes and the food substrates.

When considering health functionality of fiber-rich fractions, quite often the role of compounds that co-migrate with $\beta$-glucan are neglected. In cereals, phenolic compounds are mainly associated with water-unextractable non-starch polysaccharides (Rao and Muralikrishna, 2004). On the contrary, more than $90 \%$ phytic acid has been found in water-soluble fiber fraction of oats, which is mainly $\beta$-glucan (Frolich and Nyman, 1988). Significant amount of phytate in oat $\beta$-glucan extract (6\% in $\mathrm{dw}$ ) and in purified oat $\beta$-glucan (1.2\% in dw) has been reported (Kivela, 2011; Wang et al., 2017a). Wang et al. (2017a) have shown that the phytic acid content in purified barley $\beta$-glucan was considerably lower $(<0.3 \%)$. Nonetheless, how phytic acid associates with $\beta$-glucan, and the different phytic acid content in oat and barley $\beta$-glucan have not been understood.

Phytic acid is regarded as an anti-nutrient which deteriorates mineral absorption. It is also a natural antioxidant which chelates transition metals and/or shifts the redox of oxidation. Recently, Wang et al. $(2017 \mathrm{a}, \mathrm{b})$ have found that the residual phytate protected the oat $\beta$-glucan from oxidative degradation and retarded the lipid oxidation in emulsions containing $\beta$-glucan. Phytic acid has been shown to inhibit enzymes (e.g. trypsin and $\alpha$-amylase) within the digestive tract therefore leading to inhibition of digestion and absorption of dietary components. Phytic acid may bind to starch by hydrogen bond, bind to enzymes like $\alpha$-amylase and starch granule proteins by electrostatic interaction, or bind to enzyme cofactors such as $\mathrm{Ca}^{2+}$, therefore reducing the rate of digestion and absorption of starches (Schlemmer et al., 2009; Thompson et al., 1987). The role of phytic acid and viscosity of oat $\beta$-glucan on reduction of starch digestion has been shown separately. Nonetheless, the contribution of residual phytate in oat $\beta$-glucan to the reduction of starch digestion has not been considered and evaluated. This study aimed to investigate 1) the role of residual phytate in oat $\beta$ glucan, in addition to the viscosity by $\beta$-glucan, in the starch hydrolysis and 2) the factors influencing the phytic acid content in isolated $\beta$-glucans.

2 Materials and methods

\subsection{Isolation of $\beta$-glucan}


Oat $\beta$-glucan (OBG) and barley $\beta$-glucan (BBG) were extracted from oat bran concentrate $(14 \% \beta$ glucan "as is" basis, Oatwell, Swedish Oat Fibre, Sweden) and barley bran concentrate (16\% $\beta$ glucan"as is" basis, Bonafiber Oy Lahti, Finland) using MilliQ water (7g bran $/ 100 \mathrm{ml}$ water) at $40^{\circ} \mathrm{C}$ in a shaking incubator for $30 \mathrm{~min}$. After centrifuging the dispersions (10 $000 \mathrm{rpm}, 10 \mathrm{~min}$ ), the supernatant was collected and placed in a boiling water bath for 10 minutes to precipitate proteins. After boiling, the dispersions were centrifuged again, and the supernatant was collected. Porcine pancreatin $\left(18.75 \mathrm{mg} / \mathrm{ml}\right.$ in $\left.150 \mathrm{mM} \mathrm{NaHCO}_{3}\right)$ (Sigma, USA) was then added to the supernatant and incubated at $37^{\circ} \mathrm{C}$ for $10 \mathrm{~min}$. The enzymes were inactivated by placing the dispersions in a boiling water bath for 10 minutes before undergoing another centrifugation. The $\beta$-glucan in the collected supernatant was precipitated by gradually adding two volumes of $96 \%$ ethanol. The collected precipitate was washed by ethanol at least 3 times before oven dried at $60^{\circ} \mathrm{C}$ overnight to obtain the isolated $\beta$-glucan. The moisture content of the isolated $\beta$-glucan was around 5-7\%.

\subsection{Phytate removal}

Phytate in OBG samples was removed by ion exchange resin before ethanol precipitation according to Wang et al. (2017a). The $\beta$-glucan solution was acidified (pH 3) and stirred vigorously with activated resin (Amberlite IRA-410 Chloride form 20-25 mesh, Sigma-Aldrich, Saint Louis, USA) at $4^{\circ} \mathrm{C}$ for 2 hours before filtrated and transferred to a dialysis bag for dialysis against water (48h). Dialyzed $\beta$-glucan solution was then used for ethanol precipitation and drying.

\subsection{Characterization of isolated oat $\beta$-glucan}

The content of $\beta$-glucan, starch and phytate in the oat $\beta$-glucan extract were measured using mixedlinkage $\beta$-glucan assay, total starch assay, phytic acid (total phosphorus) assay, respectively, obtained from Megazyme, Ireland. The protein content was analyzed using Dumas combustion method (N $\times 6.25$, Vario, Germany). Quantification of minerals including calcium and phosphorus were performed with inductively coupled plasma mass spectrometer (ICP-MS, Perkin-Elmer Elan 6000, USA) with an external standard.

\subsection{Starch hydrolysis by $\alpha$-amylase}

Wheat starch (C-gel, Cargill) was dispersed in 0.05 M sodium phosphate buffer (pH 6.9) containing $0.05 \mathrm{M} \mathrm{NaCl}$ and gelatinized by boiling for $15 \mathrm{~min}$. Isolated oat $\beta$-glucans with and without phytate (OBG and OBGPR) were used to study the role of residual phytate in starch hydrolysis. OBGPR contained a higher amount of $\beta$-glucan due to the phytate removal, which was considered when preparing $\beta$-glucan solution to give the same concentration. Phytic acid sodium salt $(0.04 \%$, w/v, 
Sigma, USA) and calcium chloride ( $80 \mu \mathrm{M}$, VWR International Oy, Finland) in similar amount as in isolated $\beta$-glucan were used as controls. In order to study the effect of viscosity and intrinsic phytic acid on the starch hydrolysis, OBG and OBGPR were treated with lichenase and phytase to degrade $\beta$-glucan and phytic acid, respectively. Beta-glucan stock solutions (1\%) were incubated with lichenase (2 U/ml $\beta$-glucan, mixed-linkage $\beta$-glucan assay, Megazyme) or phytase $(0.01 \mathrm{ml} / \mathrm{ml} \beta$ glucan, Phytic acid Total Phosphorus kit, Megazyme) at $50^{\circ} \mathrm{C}$ for 1 hour. Enzyme treated solutions were heated at $100^{\circ} \mathrm{C}$ for $10 \mathrm{~min}$ to inactivate the enzymes. Viscosity value of $0.43 \%(\mathrm{w} / \mathrm{v}) \beta$-glucan and hydrolyzed $\beta$-glucan solution were also measured using a rheometer (Haake Rheostress 600, Thermo Electron $\mathrm{GmbH}$, Germany) with a cone and plate geometry $\left(35 \mathrm{~mm}, 2^{\circ}\right)$. The measurement was carried out with shear rate ranges from $10 \mathrm{~s}^{-1}$ to $100 \mathrm{~s}^{-1}$ at $20^{\circ} \mathrm{C}$. The viscosity value at a shear rate of $10 \mathrm{~s}^{-1}$ was used for comparison of samples. Triplicates were prepared for this measurement.

Three $\mathrm{ml}$ of oat $\beta$-glucan solution $(1 \%, \mathrm{w} / \mathrm{v})$ or phytic acid sodium salt solution $(0.04 \%)$ were preincubated with $0.1 \mathrm{ml}$ of $\alpha$-amylase (24U/ml, Sigma, USA) with addition of $1.9 \mathrm{ml} 0.05 \mathrm{M}$ sodium phosphate buffer ( $\mathrm{pH} 6.9$ ) at $37^{\circ} \mathrm{C}$ for $30 \mathrm{~min}$ before adding to $2 \mathrm{ml}$ gelatinized $\operatorname{starch}\left(7 \% \mathrm{w} / \mathrm{v}, 37^{\circ} \mathrm{C}\right)$. The mixtures were incubated at $37^{\circ} \mathrm{C}$ for $20 \mathrm{~min}$ with continuous shaking. The amount of reducing end was then analyzed with DNS (3,5-dinitrosalicylic acid) assay. $0.5 \mathrm{ml}$ of hydrolyzed starch was taken and added with $0.5 \mathrm{ml}$ sodium phosphate buffer (0.05 M, pH 6.9) and $1.5 \mathrm{ml}$ DNS reagent, after which the mixture was heated at $100^{\circ} \mathrm{C}$ for $5 \mathrm{~min}$. The absorbance was measured at $540 \mathrm{~nm}$ using spectrophotometer (UV-1800, Shimadzu, Japan). The DNS reagent was prepared by gradually adding $30 \mathrm{~g}$ potassium tartrate tetrahydrate in pre-dissolved 3,5-dinitrosalicylic acid $\left(1 \mathrm{~g} / 50 \mathrm{ml} \mathrm{H}_{2} \mathrm{O}\right.$, Sigma, USA). Then $20 \mathrm{ml} 2 \mathrm{M} \mathrm{NaOH}$ (Sigma, USA) was added and the volume was adjusted to $100 \mathrm{ml}$ with water before stored at dark in room temperature. Standard curve was made by using 0.1-1.2 g/L maltose solution to react with DNS reagent. The amount of reducing sugar in original OBG, degraded OBG and starch without hydrolysis were measured to differentiate the amount of reducing sugar released by the starch hydrolysis. The content (\%) of digested starch in $\beta$-glucan samples were calculated by comparing the amount of reducing sugar content in the tested samples with the control sample which was the sample containing only starch and $\alpha$-amylase. Thus the digested starch in this control sample is regarded as $100 \%$.

\subsection{Manipulation of $\beta$-glucan isolation steps}

To investigate the critical factors that influences the content of phytic acid in $\beta$-glucan, treatments including heating (Factor I), changes of $\mathrm{pH}$ (Factor II) and precipitation solvent (Factor IV), ion exchange (Factor III) and dialysis (Factor V) were separately done during $\beta$-glucan isolation (Figure 1). In Factor $\mathbf{I}$, barley bran concentrate was refluxed with hot ethanol at $70^{\circ} \mathrm{C}$ for 2 hours to inactivate 
endogenous enzymes, dried in the oven before water extraction and compared with samples without refluxing (Figure 1). Commercial oat bran concentrate was enzyme inactivated, therefore additional refluxing with ethanol was not done. Phytate is insoluble at neutral $\mathrm{pH}$ and tends to be more soluble at lower pH (Persson et al., 1998), therefore in Factor II, pH was adjusted to 3 before ethanol precipitation to compare with the samples without $\mathrm{pH}$ adjustment ( $\mathrm{pH}$ 7). In Factor III, phytate was removed by ion exchange resin before ethanol precipitation, which was described in 2.2. It has been shown that $\beta$-glucan also precipitates with $20 \%\left(\mathrm{NH}_{4}\right)_{2} \mathrm{SO}_{4}$ (Westerlund et al., 1993), therefore, the isolated $\beta$-glucan containing intrinsic phytate was dissolved in water $\left(0.4 \%\right.$, w/v) at $80^{\circ} \mathrm{C}$ for 2 hours and re-precipitated with $20 \%\left(\mathrm{NH}_{4}\right)_{2} \mathrm{SO}_{4}$ after which the re-precipitated $\beta$-glucan was dissolved and dialyzed to remove $\left(\mathrm{NH}_{4}\right)_{2} \mathrm{SO}_{4}$ (Factor IV). After dialysis, $\beta$-glucan solution was ethanol precipitated and oven dried. To study the effect of dialysis alone on the phytic acid content, the isolated $\beta$-glucan was dissolved $(0.4 \% \mathrm{w} / \mathrm{v})$ and dialyzed at $\mathrm{pH} 3(\mathrm{HCl})$ and $\mathrm{pH} 7$ (water) (Factor $\mathbf{V}$ ).

\subsection{Precipitation of pure phytic acid with different solvents}

To understand the behaviour of phytic acid in different solvents, phytic acid sodium salt (1\%, w/v) was dissolved in water and the $\mathrm{pH}$ of the solution was adjusted to $\mathrm{pH} 3.0,4.6$ (as such), and 7.0 by $\mathrm{HCl}$ and $\mathrm{NaOH}$ solutions. Phytic acid solution $(10 \mathrm{ml})$ was mixed with 1 volume $(10 \mathrm{ml}), 1.5$ volumes (15ml) or 2 volumes $(20 \mathrm{ml})$ of $96 \%$ ethanol. The phytic acid solution ( $\mathrm{pH}$ not adjusted) was also mixed with 2 volumes of $30 \%\left(\mathrm{NH}_{4}\right)_{2} \mathrm{SO}_{4}$ to reach $20 \%$ in the final mixture. Additionally, myoinositol solution ( $1 \%$, Sigma, USA) was mixed with 2 volumes $96 \%$ ethanol. All the mixtures were centrifuged at $7000 \mathrm{rpm}$ for $10 \mathrm{~min}$. The supernatant in each tube was carefully descanted and the precipitate in the bottom of the tube was oven dried at $60^{\circ} \mathrm{C}$ overnight before weighing. The percentage of precipitated phytic acid in each condition was calculated as:

Phytic acid precipitate $(\%)=\left(\mathrm{W}_{\text {total }}-\mathrm{W}_{\text {tube }}\right) / \mathrm{W}_{\text {phytic acid }} * 100 \%$

where $\mathrm{W}_{\text {total }}$ is the weight of tube and precipitate, $\mathrm{W}_{\text {tube }}$ is the weight of empty tube, and $\mathrm{W}_{\text {phytic acid }}$ is the total weight of added phytic acid in the solution which is $0.1 \mathrm{~g}(10 \mathrm{ml} * 1 \%)$.

\subsection{Statistical analysis}

Statistical analyses were performed on Statistical Package for the Social Science (SPSS Statistics version 23, IBM), using one-way analysis of variance (ANOVA) followed by post hoc Turkey test. Differences were considered as significant at $p<0.05$. All the results were presented as means \pm standard error.

\section{Results and Discussion}




\subsection{Starch hydrolysis in vitro}

\subsubsection{Role of phytic acid and calcium from $\beta$-glucan in starch hydrolysis}

OBG contained 3.9\% phytic acid and OBGPR contained $0.6 \%$ phytic acid. The starch and protein content in OBG was $2.0 \%$ and $8.2 \%$, respectively. The intrinsic phytate in OBG played a role in the retardation of starch hydrolysis. OBG (0.43\%) significantly reduced the starch hydrolysis (79\%) after 20 min comparing to the control samples without OBG addition (100\%) (Figure 2). Pre-incubation of OBG samples or phytic acid with a-amylase was needed for this retardation effect, which was also shown by earlier studies (Deshpande and Cheryan, 1984). When phytate was removed from OBG, the starch hydrolysis was 94\%. Addition of pure phytic acid (in similar amount as in OBG) in OBGPR contributed to the reduction of starch hydrolysis $(84 \%)$, whereas the reduction extent was less than OBG which contained intrinsic phytate. Pure phytic acid alone reduced the starch hydrolysis to $91 \%$. This agrees with the results shown by Knuckles and Betschart (1987) that 5mM phytate reduced starch digestion (salivary alpha-amylase induced) to $86 \%$ at pH 6.9. Similarly, Thompson et al. (1987) have shown that endogenous and added phytic acid in navy bean flour reduced the in vitro rate of starch digestion and blood glucose response in humans. They suggested that phytate reduced starch digestion by directly binding with starch or interaction with amylase enzymes.

Björck and Nyman (1987) showed that the addition of phytic acid inhibited the early stage of starch hydrolysis (<30 min) but had negligible influence on a-amylase activity and starch hydrolysis after $1 \mathrm{~h}$ even though preincubation of phytic acid and enzyme was performed. Later on in 1989, the same authors showed that phytic acid did not inhibit the in-vivo starch digestion with a rat model (Nyman and Björck, 1989). The diet contained raw wheat starch, sugar-beet fiber and casein as protein source, which are all possible substrates to interact with phytic acid. When the interactive sites of phytic aicd are fully occupied by the substrates, the chelation or binding ability of phytic acid to enzymes and metals are reduced.

Calcium is known to enhance $\alpha$-amylase activity, and pure calcium at $0.8 \mu \mathrm{M}$ (same amount in OBG) increased the starch hydrolysis to $250 \%$ (Figure 3 ) comparing to control samples without calcium addition. According to Thompson et al. (1987), molar ratio of Ca: PA as 0.57 reduced the starch digestion, the increase of this ratio to 2.2 reduced starch digestion but had less reduction. Yoon et al. (1983) haven shown that high Ca concentration (18.35 Ca/ PA molar ratio) enhanced the in vitro starch digestibility. This agrees with our observation that when $0.5 \mathrm{mM} \mathrm{CaCl} 2$ was added, starch hydrolysis was not reduced by OBG containing intrinsic phytate and OBGPR with phytic acid addition. 
Ion exchanging and dialysis removed phytic acid as well as minerals including $\mathrm{Ca}$. When the same amount of phytic acid and Ca were added back to OBGPR, the starch hydrolysis was not inhibited but enhanced. The added pure phytic acid and Ca could not form the same complex as intrinsic phytate in OBG. The enhancing effect of Ca overwhelmed the inhibitory effect of phytic acid. Wang et al. (2017b) also reported that the added phytic acid was not as effective as intrinsic phytic acid retarding $\beta$-glucan oxidative degradation.

\subsubsection{Role of viscosity in starch hydrolysis}

OBG and OBGPR at $0.43 \%$ concentration had similar viscosity $\left(300 \mathrm{mPa} \cdot \mathrm{s}\right.$ at shear rate $\left.10 \mathrm{~s}^{-1}\right)$ and phytate removal did not affect the viscosity of $\beta$-glucan. OBGPR reduced the starch hydrolysis compared to the control samples although the phytate was removed, which indicates that other factors such as viscosity contributed to the reduction. Addition of lichenase in OBG and OBGPR significantly degraded the $\beta$-glucan molecules and decreased the viscosity to $10 \mathrm{mPa} \cdot \mathrm{s}$. After $\beta$-glucan degradation, the starch hydrolysis was enhanced (Figure 3). This was expected as the previous studies have shown that viscosity of $\beta$-glucan inhibits enzyme accessibility to starch and reduces starch hydrolysis (Symons and Brennan, 2004; Zhang et al., 2017). After hydrolysis, OBG increased starch hydrolysis more than OBGPR likely because the higher content of minerals in OBG which were released and promoted the starch hydrolysis.

Phytase was used to degrade the endogenous phytate and release minerals. Additionally, phytase also degraded $\beta$-glucan and lowered its viscosity to $16 \mathrm{mPa} \cdot \mathrm{s}$. Jaskari et al. (1995) also observed that phytase preparation used for hydrolysis of phytic acid caused a reduction in viscosity of oat bran slurries due to the side effect of phytase. Phytase addition in OBG considerably increased the starch hydrolysis ( 2 times) because of the viscosity loss, phytate degradation and mineral (Ca) release.

\subsection{Changes of phytic acid content during isolation of $\beta$-glucan}

Oat and barley bran concentrates contained $1.3 \%$ and $0.6 \%$ phytic acid $(\mathrm{w} / \mathrm{w})$, respectively. Previous studies have reported that the phytic acid content in oat and barley grain is $0.4-1.2 \%$ dry matter basis, and higher amount can be found in bran fractions (Garci'a-Estepa et al., 1999). The isolated oat $\beta$ glucan $(\mathrm{OBG})$ produced with regular water extraction protocol contained $66 \% \beta$-glucan and 3.9\% phytic acid ("as is" basis) (Table 1). With the same protocol, the isolated barley $\beta$-glucan (BBG) had similar level of $\beta$-glucan (62\%) but significantly lower content of phytic acid $(0.5 \%)$. We investigated the influencing factors on the phytate content of $\beta$-glucan samples, and found that the procedure for $\beta$-glucan isolation was of importance for the co-migration of phytate. 
Refluxing the barley bran concentrate with hot ethanol before water extraction (Factor I, Table 1) effectively increased the phytic acid content to $2.2 \%$, and increased the viscosity of the extract from 9 to $50 \mathrm{mPa} \cdot \mathrm{s}$. Studies have used heat treatment to inactivate the endogenous $\beta$-glucanases and obtain $\beta$-glucan with high molecular weight (Zheng et al., 2011). According to the current results, the ethanol refluxing also inactivated the endogenous phytase, therefore increased the amount of phytate in the isolated barley $\beta$-glucan. This was also evidenced by a considerable reduction of the free phosphorus content from 634 to $106 \mathrm{mg} / 100 \mathrm{~g}$ in BBG after refluxing (Table 1). We could infer that the heat treatment of the commercial oat bran concentrate contributed to the high amount of phytate in OBG. The phytic acid content in isolated $\beta$-glucan was more than 2 times higher than in the starting raw material after heat treatment, which indicated that phytic acid accumulated during $\beta$-glucan isolation. Phytic acid also carried the cations (most abundantly $\mathrm{Ca}$ and $\mathrm{Mg}$ ), which resulted in an increase of mineral content in isolated $\beta$-glucan compared to the starting bran concentrates (Table 1). Wang et al. (2017a) also reported that the mineral content in commercial $\beta$-glucans was higher in the samples containing higher amount of residual phytate. ${ }^{7}$

Precipitation solvents chosen for $\beta$-glucan collection after extraction made a difference on phytate content in the final extract. Ethanol (50-70\%) is commonly used as a solvent to precipitate soluble fibers in lab scale as well as in industrial scale. In our study, we used 2 volumes of ethanol (67\%) to precipitate $\beta$-glucan after extraction. Surprisingly, we found that phytic acid (sodium salt) itself also precipitated (100\%) under the same condition (Table 2 ). This largely explained the high phytic acid content in isolated $\beta$-glucan. The extracted phytate from raw material co-precipitated with $\beta$-glucan by ethanol. When 1.5 volumes of ethanol was added, the content of precipitated phytic acid reduced to $24 \%$, and no precipitation of phytic acid was observed when adding 1 volume ethanol (Table 2). In addition, ammonium sulphate $(20 \%, \mathrm{w} / \mathrm{v})$ has been known to precipitate $\beta$-glucans, and used in the purification and separation of $\beta$-glucan and other cereal gums (Izydorczyk et al., 1998; Westerlund et al., 1993). The phytic acid content in OBG precipitated by $20 \%\left(\mathrm{NH}_{4}\right)_{2} \mathrm{SO}_{4}$ was only $0.2 \%$ (Factor IV, Table 1) because we found that pure phytic acid did not precipitate with $20 \%\left(\mathrm{NH}_{4}\right)_{2} \mathrm{SO}_{4}(\mathrm{Table}$ 2). This indicates that phytic acid and $\beta$-glucan are not covalently linked and the co-migration can be altered by changing precipitation solvents. The co-migration of phytic acid with water soluble fiber from oat was first reported by Frolich and Nyman (1988) and later Kivelä et al. (2011) observed 6\% of phytic acid in the isolated $\beta$-glucan ${ }^{6}$. In fact, both studies have used ethanol in the collection of $\beta$ glucan, which caused the co-precipitation of phytic acid and resulted in the high phytic acid content in the final $\beta$-glucan extracts. This also explained the presence of high amount of minerals in the soluble fraction of oats noticed by Frolich and Nyman (1988). Myo-inositol without phosphorylation 
did not precipitate with ethanol (Table 2) which indicates that the co-precipitated phytates in $\beta$-glucan extract are mostly highly phosphorylated inositol phosphate esters. It has been shown that higher phosphorylation degree correlated to better metal binding capacity and antioxidant activity (Miyamoto et al., 2000; Sandberg et al., 1999). Therefore, co-precipitated phytate in $\beta$-glucan can play a big role in metal binding and antioxidant activities as shown by Wang et al. (2017b). Other precipitation solvents such as 50\% isopropyl alcohol and 50\% acetone have been used (Lee et al., 2017) and the behaviour of phytic acid in these solvents should be investigated before using.

On the other hand, the precipitation behaviour under ethanol is not exclusive to phytic acid and polysaccharides. Previous studies have shown that calcium and magnesium phosphate also precipitated with ethanol (Babaie et al., 2015). Moreover, ethanol ( $>64 \%$ ) has been used to precipitate DNA which contains high amount of phosphate groups in the backbone (Green and Sambrook, 2016). The highly charged phosphate makes DNA polar and water soluble. It is suggested that adding ethanol to solution enhanced the electrical attraction between phosphate groups and any positive ions present in solution and the formation of DNA precipitation. The precipitation of phytic acid by ethanol may have the same mechanisms as for DNA. We showed that the myo-inositol which does not contain phosphorus group did not precipitate with ethanol.

Acidifying the $\beta$-glucan solution before ethanol precipitation reduced the phytate content from 3.9\% to $2.6 \%$ for oat $\beta$-glucan and from $0.5 \%$ to $0.2 \%$ for barley $\beta$-glucan (Factor II, Table 1 ). It is wellknown that lowering the $\mathrm{pH}$ largely enhances the solubility of phytate in water (Persson et al., 1998), however, the solubility of phytic acid in ethanol and the role of $\mathrm{pH}$ were not reported in literature. We found that pure phytic acid (sodium salt) precipitated with the highest extent (about 100\%) at neutral $\mathrm{pH}$ when 2 volumes of ethanol were added (Table 2), which was also the conditions used for regular $\beta$-glucan extraction. The precipitation of phytic acid reduced to $64 \%$ at $\mathrm{pH} 4.6$ and $40 \%$ at $\mathrm{pH}$ 3.0. This explained the reduction of phytate content in OBG and BBG when the $\beta$-glucan solutions were acidified before ethanol precipitation.

Dialysis at neutral $\mathrm{pH}$ before ethanol precipitation reduced the phytic acid content to $3.2 \%$ in $\mathrm{OBG}$, whereas dialysis at $\mathrm{pH} 3$ reduced it to $0.6 \%$ (Factor $\mathbf{V}$, Table 1). Phytate at neutral $\mathrm{pH}$ is mostly insoluble and may complex with proteins, minerals and $\beta$-glucan forming aggregates that could not effectively pass through dialysis bag (cut-off $14 \mathrm{kDa}$ ). At low $\mathrm{pH}$, phytate is more soluble and phytate complex disassociates and could pass through the dialysis bag. Zielke et al. (2018) have reported that protein and $\beta$-glucan formed aggregates via electrostatic interactions depending on $\mathrm{pH}$ and the minor phosphorus in $\beta$-glucan was suggested to contribute to the interaction. In their study, only the free phosphorus content was measured without considering phytate which is the major storage of 
phosphorus and contributor to electric charges. Therefore, the role of phytate in aggregation behaviour of $\beta$-glucan and its interactions with protein at different $\mathrm{pH}$ should be considered.

283

Ion exchange followed by dialysis ( $\mathrm{pH} 3$ ) removed $85 \%$ of the phytic acid in OBG (Factor III, Table 1). With the same anion exchange resin, Kumagai et al. (2002) removed $90 \%$ of the phosphorus in defatted soybeans. In our study, only dialysis without ion exchanging at low $\mathrm{pH}$ removed similar amount of phytic acid. Ion exchanging may reduce the time used for the phytate removal but unneccesarily the amount of removed phytate. Phytate removal also reduced considerably the amount of intrinsic minerals. The content of $\mathrm{Ca}$ and $\mathrm{Mg}$ in $\mathrm{OBG}$ reduced from 330 to $90 \mathrm{mg} / 100 \mathrm{~g}$ and from 610 to $160 \mathrm{mg} / 100 \mathrm{~g}$, respectively, after phytate removal (OBGPR) (Table 1). The mechanical reduction of phytate e.g. by milling also causes substantial loss of minerals.

We showed that the phytate content in $\beta$-glucan varied largely due to the isolation procedure. The differences of phytate content in $\beta$-glucan material may influence the results and conclusions. The co-migrated phytate can offer $\beta$-glucan sample such properties as metal binding ability and antioxidant activity. Wang et al. (2017a,b) have shown that the differences of oat and barley $\beta$-glucans in iron binding capacity and oxidative stability were due to their phytate content instead of structural differences.

\section{Conclusion}

Our study demonstrated that not only the viscosity but also the co-migrated phytic acid and minerals in $\beta$-glucan play a role in the retardation of starch hydrolysis in vitro. The phytic acid content in $\beta$ glucan samples varied substantially according to the isolation procedure. The precipitation behavior of phytic acid in ethanol was the main reason for the high content of phytic acid in isolated $\beta$-glucan produced by ethanol precipitation. Ammonium sulphate, another precipitation solvent used in $\beta$ glucan isolation, could not precipitate phytic acid leading to a low content of phytic acid in the isolated $\beta$-glucan. Inactivation of the endogenous phytase contributed to the high content of phytic acid. $\mathrm{pH}$ lowering before ethanol precipitation, dialysis of the extract at low $\mathrm{pH}$, or anion exchanging reduced the phytic acid content. The contribution of the intrinsic phytate should be taken into consideration when evaluating the physico-chemical and physiological properties of $\beta$-glucans.

\section{Acknowledgement}

The authors wish to gratefully thank the Academy of Finland (Project number 258821) and Graduate School of University of Helsinki for their financial support. 


\section{REFERENCES}

Babaie, E., Zhou, H., Lin, B., Bhaduri, S. B.,2015. Influence of ethanol content in the precipitation medium on the composition, structure and reactivity of magnesium-calcium phosphate. Mat Sci \& Eng: C, 53, 204-211.

Björck, I. M., Nyman, M. E., 1987. In vitro effects of phytic acid and polyphenols on starch digestion and fiber degradation. J Food Sci, 52(6), 1588-1594.

Deshpande, S., Cheryan, M., 1984. Effects of Phytic Acid, Divalent Cations, and Their Interactions on $\alpha$-Amylase Activity. J Food Sci, 49(2), 516-519.

Frølich, W., Nyman, M., 1988. Minerals, phytate and dietary fiber in different fractions of oat-grain. J Cereal Sci, 7, 7382.

Garci'a-Estepa, R.M., Guerra-Hernández, E., García-Villanova, B., 1999. Phytic acid content in milled cereal products and breads. Food Res Int, 32, 217-221.

Green, M. R., Sambrook, J., 2016. Precipitation of DNA with ethanol. Cold Spring Harb Protoc, 1116-1120. doi:10.1101/pdb.prot093377

Izydorczyk, M. S., Macri, L. J., MacGregor, A. W., 1998. Structure and physicochemical properties of barley non-starch polysaccharides - I. water-extractable $\beta$-glucans and arabinoxylans. Carbohydr Polym, 35(3-4), 249-258.

Jaskari, J., Henriksson, K., Nieminen, A., Suortti, T., Salovaara, H., Poutanen, K., 1995. Effect of hydrothermal and enzymic treatments on the viscous behavior of dry-and wet-milled oat brans. J Cereal Chem, 72(6), 625-631.

Kim, H. J., White, P. J., 2013. Impact of the molecular weight, viscosity, and solubility of $\beta$-glucan on in vitro oat starch digestibility. J Agric Food Chem, 61, 3270-3277.

Kivelä, R., 2011. Non-enzymatic degradation of $(1 \rightarrow 3),(1 \rightarrow 4)-\beta$-D-glucan in aqueous processing of oats. Doctoral dissertation (article-based). University of Helsinki.

Knuckles, B., Betschart, A., 1987. Effect of phytate and other myo-inositol phosphate esters on $\alpha$-amylase digestion of starch. J Food Sci, 52(3), 719-721.

Kumagai, H., Ishida, S., Koizumi, A., Sakurai, H., 2002. Preparation of phytate-removed deamidated soybean globulins by ion exchangers and characterization of their calcium-binding ability. J Agric Food Chem, 50(1), 172-176.

Lee, Y.-T., Puligundla, P., Schwarz, P. B., 2017. Molecular weight, solubility and viscosity of $\beta$-glucan preparations from barley pearling byproducts. Sains Malaysiana, 46 (5), 713-718.

Miyamoto, S., Kuwata, G., Imai, M., Nagao, A., Terao, J., 2000. Protective effect of phytic acid hydrolysis products on iron-induced lipid peroxidation of liposomal membranes. Lipid, 35(12), 1411-3.

Mäkeläinen, H., Anttila, H., Sihvonen, J., Hietanen, R., Tahvonen, R., Salminen, E., Mikola, M., Sontag-Strohm, T., 2007. The effect of $\beta$-glucan on the glycemic and insulin index. Eur J Clin Nutr, 61, 779-785.

Nyman, M. E., Björck, I. M., 1989. In vivo effects of phytic acid and polyphenols on the bioavailability of polysaccharides and other nutrients. J Food Sci, 54(5), 1332-5. 
Persson, H., Turk, M., Nyman, M., Sandberg, A. S., 1998. Binding of $\mathrm{Cu}^{2+}, \mathrm{Zn}^{2+}$, and $\mathrm{Cd}^{2+}$ to inositol Tri-, Tetra-, Penta-, hexaphosphates. J Agric Food Chem, 46, 3194-3200.

Rao, R. S. P., Muralikrishna, G., 2004. Non-starch polysaccharide-phenolic acid complexes from native and germinated cereals and millet. J Food Chem, 84(4), 527-531.

Regand, A., Chowdhury, Z., Tosh, S. M., Wolever, T. M. S., Wood, P., 2011. The molecular weight, solubility and viscosity of oat $\beta$-glucan affect human glycemic response by modifying starch digestibility. J Food Chem, 129, 297-304.

Sandberg, A.S, Brune, M., Carlsson, N., Hallberg, L., 1999. Inositol phosphates with different numbers of phosphate groups influence iron absorption in humans. Am J Clin Nutr, 70, 240-246.

Schlemmer, U., Frølich, W., Prieto, R. M., Grases, F., 2009. Phytate in foods and significance for humans: Food sources, intake, processing, bioavailability, protective role and analysis. Molecular Nutrition \& Food Research, 53, 330-375.

Symons, L., Brennan, C., 2004. The Influence of $(1 \rightarrow 3)(1 \rightarrow 4)-\beta$-D-Glucan-rich Fractions from Barley on the Physicochemical Properties and In Vitro Reducing Sugar Release of White Wheat Breads. J Food Sci, 69 (6), C463C467.

Thompson, L. U., Button, C. L., Jenkins, D. J., 1987. Phytic acid and calcium affect the in vitro rate of navy bean starch digestion and blood glucose response in humans. Am J Clin Nutr, 46, 467-473.

Wang, Y. -J., Maina, N. H., Ekholm P., Lampi, A. -M., Sontag-Strohm, T., 2017a. Retardation of oxidation by residual phytate in purified cereal $\beta$-glucans. Food Hydrocoll, 66, 161-167.

Wang, Y. -J., Zhan, R., Sontag-Strohm, T., Maina, N. H., 2017b. The protective role of phytate in the oxidative degradation of cereal $\beta$-glucans. Carbohyd Polym, 169, 220-226.

Westerlund, E., Andersson, R., Åman, P., 1993. Isolation and chemical characterization of water-soluble mixed-linked $\beta$ glucans and arabinoxylans in oat milling fractions. Carbohyd Polym, 20(2), 115-123.

Yoon, J. H., Thompson, L. U., Jenkins, D., 1983. The effect of phytic acid on in vitro rate of starch digestibility and blood glucose response. Am J Clin Nutr, 38(6), 835-842.

Zhang, J., Luo, K., Zhang, G., 2017. Impact of native form oat $\beta$-glucan on starch digestion and postprandial glycemia. $J$ Cereal Sci, 73, 84-90.

Zheng, X., Li, L., Wang, Q., 2011. Distribution and molecular characterization of $\beta$-glucans from hull-less barley bran, shorts and flour. Int J Mol Sci, 12(3), 1563-1574.

Zielke, C., Lu, Y., Poinsot, R., Nilsson, L., 2018. Interaction between cereal $\beta$-glucan and proteins in solution and at interfaces. Colloids Surf B Biointerfaces., 162, 256-264. 
Captions of figures:

Figure 1. The procedure of $\beta$-glucan isolation and the treatments (factors) in various steps during isolation. To investigate the effect of each factor on phytic acid content, the corresponding treatment was independently done.

Figure 2. Starch hydrolysis in the presence of isolated $\beta$-glucan or phytic acid after $20 \mathrm{~min}$ at $37^{\circ} \mathrm{C}$. Starch hydrolysis ( $\operatorname{starch}+\alpha$-amylase) without addition of any other compounds are control samples regarded as base line (100\%) for comparison. OBG is isolated oat $\beta$-glucan containing phytate, OBGPR is phytate removed OBG, PA is phytic acid sodium salt $(0.04 \mathrm{w} / \mathrm{v})$.

Figure 3. Digested starch in the presence of hydrolysed $\beta$-glucan or calcium after 20 min at $37^{\circ} \mathrm{C}$. Starch hydrolysis ( $\operatorname{starch}+\alpha$-amylase) without addition of any other compounds are control samples regarded as base line (100\%) for comparison. OBG is isolated oat $\beta$-glucan, OBGPR is phytate removed OBG, PA is phytic acid sodium salt. 
Table 1. Phytate and mineral content of oat and barley bran concentrates and isolated $\beta$-glucan.

\begin{tabular}{|c|c|c|c|c|c|c|c|}
\hline & $\beta$-Glucan samples & Factor & $\begin{array}{l}\beta \text {-Glucan } \\
\%\end{array}$ & $\begin{array}{l}\text { Phytic acid } \\
\%\end{array}$ & $\begin{array}{l}\text { Free } \mathrm{P} \\
\mathrm{mg} / 100 \mathrm{~g}\end{array}$ & $\begin{array}{l}\mathrm{Ca} \\
\mathrm{mg} / 100 \mathrm{~g}\end{array}$ & $\begin{array}{l}\mathrm{Mg} \\
\mathrm{mg} / 100 \mathrm{~g}\end{array}$ \\
\hline \multirow[t]{7}{*}{ Oat } & Bran concentrate & & 14 & $1.27 \pm 0.02^{\mathrm{e}}$ & $88.4 \pm 0.7^{f}$ & $120 \mathrm{~b}$ & 290 \\
\hline & Isolated $\beta$-glucan (OBG) & & $66 \pm 2 b c$ & $3.86 \pm 0.09^{\mathrm{a}}$ & $109.6 \pm 0.8^{c}$ & 330 & 610 \\
\hline & $\begin{array}{l}\text { OBG } \\
+ \text { acidified before ethanol } \\
\text { precipitation }(\mathrm{pH} 3)\end{array}$ & II & $69 \pm 2 \mathrm{~b}$ & $2.59 \pm 0.02^{\mathrm{c}}$ & $77.5 \pm 0.1 \mathrm{~g}$ & & \\
\hline & $\begin{array}{l}\text { OBGPR } \\
\text { (phytate removal) }\end{array}$ & III & $72.7 \pm 0.3^{\text {a }}$ & $0.60 \pm 0.05^{\mathrm{f}}$ & $88 \pm 2^{f}$ & 86 & 160 \\
\hline & $\begin{array}{l}\mathrm{OBG} \\
+\left(\mathrm{NH}_{4}\right)_{2} \mathrm{SO}_{4} \text { re-precipitation }\end{array}$ & IV & NM & $0.23 \pm 0.01^{\mathrm{g}}$ & $73.1 \pm 1.0^{\mathrm{h}}$ & & \\
\hline & $\mathrm{OBG}+$ dialysis $(\mathrm{pH}$ as such) & $\mathbf{V}$ & NM & $3.20 \pm 0.05^{b}$ & $120 \pm 2 \mathrm{~b}$ & & \\
\hline & $\mathrm{OBG}+$ dialysis at $\mathrm{pH} 3$ & $\mathbf{V}$ & NM & $0.57 \pm 0.01^{\mathrm{f}}$ & $97 \pm 2 \mathrm{e}$ & & \\
\hline \multirow[t]{5}{*}{ Barley } & Bran concentrate & & 16 & $0.61 \pm 0.06^{\mathrm{f}}$ & $26.4 \pm 0.9^{j}$ & & \\
\hline & Isolated $\beta$-glucan (BBG) & & $62 \pm 2 d$ & $0.51 \pm 0.04^{\mathrm{f}}$ & $634 \pm 11^{a}$ & & \\
\hline & $\mathrm{BBG}$ & & & & & & \\
\hline & $\begin{array}{l}+ \text { hot ethanol refluxing before } \\
\text { isolation }\end{array}$ & $\mathbf{I}$ & $69.2 \pm 0.9^{b}$ & $2.24 \pm 0.07^{\mathrm{d}}$ & $106.4 \pm 0.8^{\mathrm{d}}$ & & \\
\hline & $\begin{array}{l}\text { BBG } \\
+ \text { acidified before ethanol } \\
\text { precipitation ( } \mathrm{pH} \mathrm{3)}\end{array}$ & II & $75 \pm 2$ a & $0.21 \pm 0.01 \mathrm{~g}$ & $60.5 \pm 1.2^{\mathrm{i}}$ & & \\
\hline
\end{tabular}

a-j means within a column with different superscripts differ $(p<0.05)$

Table 2. Precipitation of phytic acid sodium salt $\left(1 \%\right.$, w/v) with ethanol or $\left(\mathrm{NH}_{4}\right)_{2} \mathrm{SO}_{4}$ at different $\mathrm{pH}$.

\begin{tabular}{lll}
\hline Solvent & $\mathrm{pH}$ & Precipitated phytic acid \\
\hline 2 volumes EtOH & 3.0 & $39.9 \pm 0.2^{\mathrm{c}}$ \\
& 4.6 & $64.1 \pm 0.6^{\mathrm{b}}$ \\
& 7.0 & $101 \pm 0.4^{\mathrm{a}}$ \\
1.5 volumes EtOH & 4.6 & $24.0 \pm 1.0^{\mathrm{d}}$ \\
1 volume $\mathrm{EtOH}$ & 4.6 & $\mathrm{ND}$ \\
$20 \%\left(\mathrm{NH}_{4}\right)_{2} \mathrm{SO}_{4}$ & 4.6 & $\mathrm{ND}$ \\
2 volumes $\mathrm{EtOH}$ & 4.6 & $\mathrm{ND}$ (Myo-inositol)
\end{tabular}

Note: ND means not detected. One volume means the same volume as phytic acid solution. Three replicates were prepared for each sample. ${ }^{\text {a-d }}$ means within a column with different superscripts differ $(p<0.05)$. 


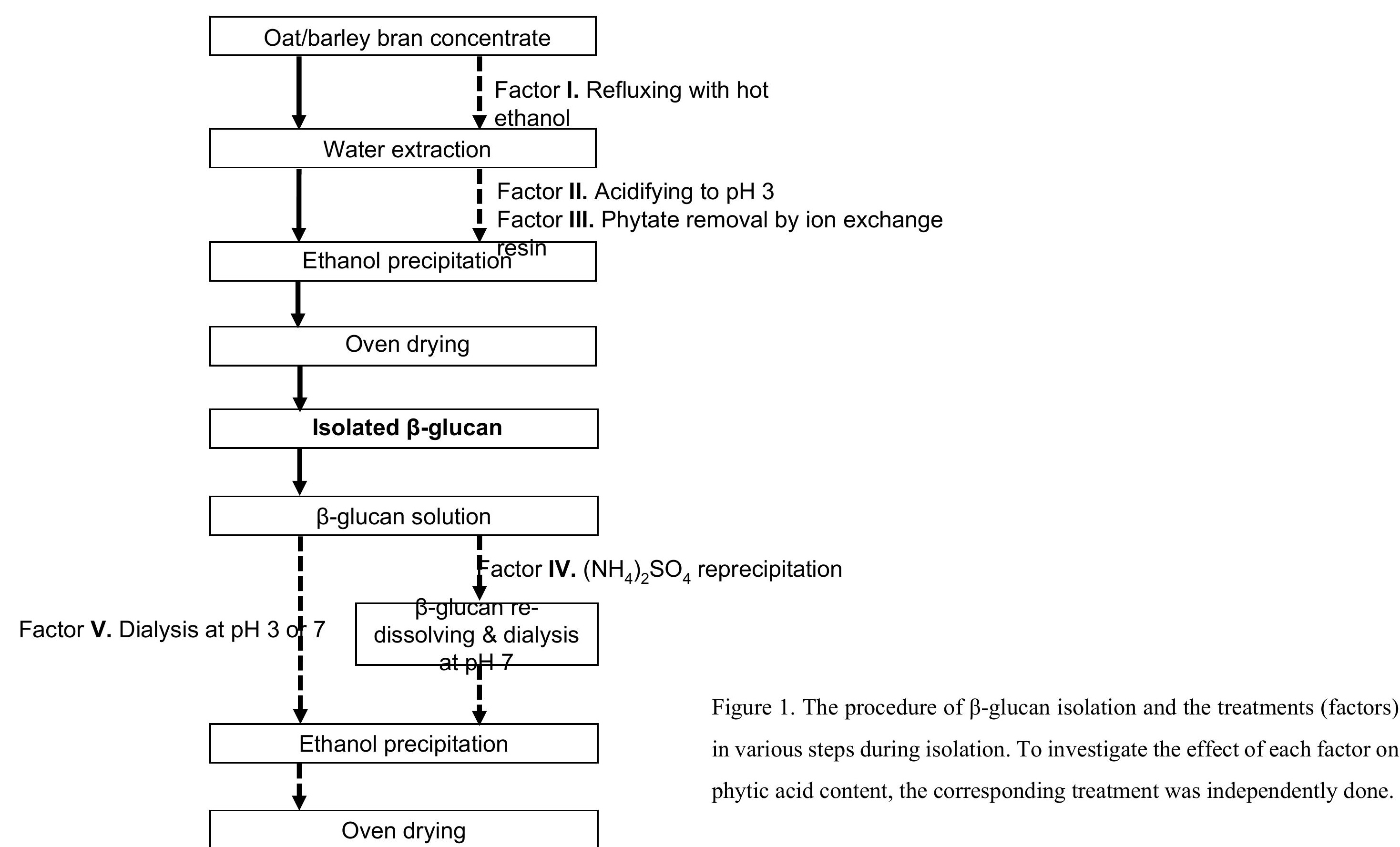




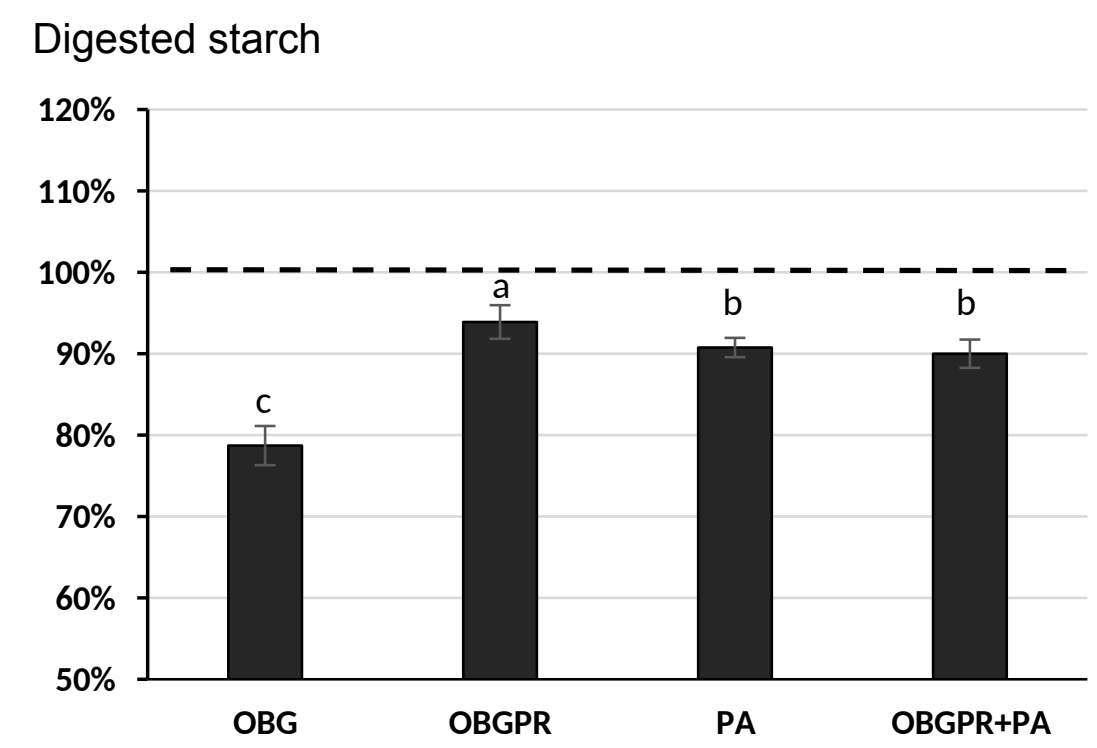

Figure 2. Starch hydrolysis in the presence of isolated $\beta$-glucan or phytic acid after $20 \mathrm{~min}$ at $37^{\circ} \mathrm{C}$. Starch hydrolysis (starch $+\alpha$-amylase) without addition of any other compounds are control samples regarded as base line (100\%) for comparison. OBG is isolated oat $\beta$-glucan containing phytate, OBGPR is phytate removed OBG, PA is phytic acid sodium salt $(0.04 \mathrm{w} / \mathrm{v}){ }^{\mathrm{a}-\mathrm{c}}$ means bars with different superscripts differ $(p<0.05)$. 


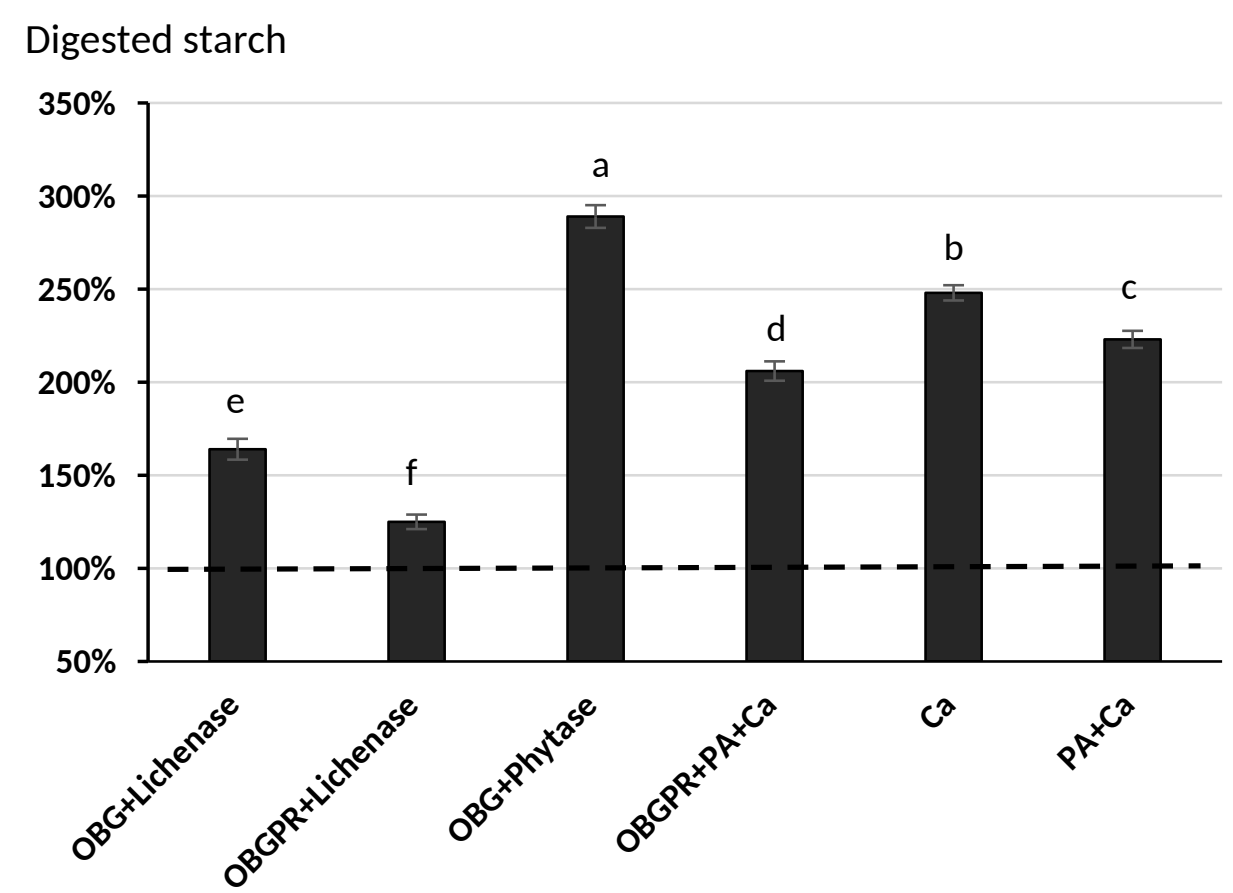

Figure 3. Digested starch in the presence of hydrolysed $\beta$-glucan or calcium after $20 \mathrm{~min}$ at $37^{\circ} \mathrm{C}$. Starch hydrolysis (starch $+\alpha$-amylase) without addition of any other compounds are control samples regarded as base line (100\%) for comparison. OBG is isolated oat $\beta$-glucan, OBGPR is phytate removed OBG, PA is phytic acid sodium salt. ${ }^{\text {a-f }}$ means bars with different superscripts differ $(p<0.05)$. 


\section{Statement}

This is to state that the work described has not been published previously, that it is not under consideration for publication elsewhere, that its publication is approved by all authors and tacitly or explicitly by the responsible authorities where the work was carried out, and that, if accepted, it will not be published elsewhere in the same form, in English or in any other language, including electronically without the written consent of the copyright-holder.

Yu-Jie Wang

Lausanne, Switzerland

17.9.2019 


\section{Author statement}

Yu-Jie Wang: Conceptualization, Methodology, Validation, Formal analysis, Investigation, Writing original draft, Review \& Editing, Visualization

Lingxi Yang: Investigation, Writing Review \& Editing

Tuula Sontag-Strohm: Conceptualization, Supervision, Writing Review \& Editing,

Funding acquisition 